\title{
Ecological Risk Assessment of Land Use Change in the Northeast China: A Case Study of Linjiang Area
}

\author{
Taohong Zou, Jiquan Zhang, and Kunihiko Yoshino
}

\begin{abstract}
In the context of land use change, the regional environment in the Northeast China is affected by various factors. Combining with the theory of risk assessment, the evaluation indicators of ecological risk assessment were chose from aspects of hazard, exposure and vulnerability in this paper. And then the comprehensive evaluation model was utilized to obtain the ecological risk index value at a gird scale of $30 \mathrm{~m} \times 30 \mathrm{~m}$. The results showed that, although the ecological risk value is not so high in the whole Linjiang area because of the special geographical location, the forest quality and structure has been severely degraded, due to the imbalance of forest harvesting and tending in the recent decades. It can be seen from the distribution map that the ecological risk in Linjiang area has a very significant phenomenon of spatial difference.
\end{abstract}

Index Terms-Ecological risk assessment, ecological risk indicator system, land use change, Linjiang area.

\section{INTRODUCTION}

The land cover change induced by the land use change is a problem closely related to natural and human process [1]. The utilization, development and the transformation of environment destroy the dynamic balance of human being and environment [2] that aroused a series of bad effects resulting in the deterioration of environmental quality and function. With the development of industry and expansion of urban, the range of human impacts on the environment is constantly increasing and the impacts are becoming serious [3]. The environment issues caused by land development break the dynamic equilibrium between humans and environment that have direct or potential threat on human survival and reproduction [4].

The land use change has a profound impact on the natural environment [5] by affecting the climate, soil, hydrological and topographic system, meanwhile, lead to the change of ecosystem structure and function [6], such as decrease of biodiversity and dramatic change in landscape structure.

In this paper, the relationship between land use change and ecological environment was analyzed from the perspective of landscape ecology. Considering that the impact of land use change within the reasonable range on environment can automatically recover through its resilience capacity [7], however, land use change out of reasonable range might led to

Manuscript received April 15, 2015; revised June 18, 2015.

Zou Taohong is with the Graduate School of Systems and Information Engineering, University of Tsukuba, Ibaraki, Japan (e-mail: zoutaohong@gmail.com).

Zhang Jiquan is with the School of Environment, Northeast Normal University, China (e-mail: zhangjq022@nenu.edu.cn).

Yoshino Kunihiko is with the Department of Systems and Information Engineering, University of Tsukuba, Japan (e-mail: sky@sk.tsukuba.ac.jp). fragmentation of ecosystem landscape and changes in landscape patterns [8], finally cause negative impacts on the environment. Therefore, indicators are chosen from hazard, exposure and vulnerability to evaluate the ecological risk in Linjiang area.

\section{STUdy Site}

Linjiang area locates at the southeast part of Jilin province, China, foot of Changbai Mountain, and covers about 3000 $\mathrm{km}^{2}$ from $126^{\circ} 34^{\prime}$ to $127^{\circ} 49^{\prime} \mathrm{E}$ and $41^{\circ} 31^{\prime}$ to $42^{\circ} 03^{\prime} \mathrm{N}$ (Fig. 1 ), with a total population of 216 thousand people. Under the control of temperate continental monsoon climate, the study site has distinct four seasons. The annual average temperature is about 2-4 degree and the annual total precipitation is around $800 \mathrm{~mm}$.

The major land cover type is forest with an area of 2380 $\mathrm{km}^{2}$, occupies about $79 \%$ of the total area. Due to the high vegetation coverage, this area is abundant in natural resources, such as mineral resources and wildlife resource.

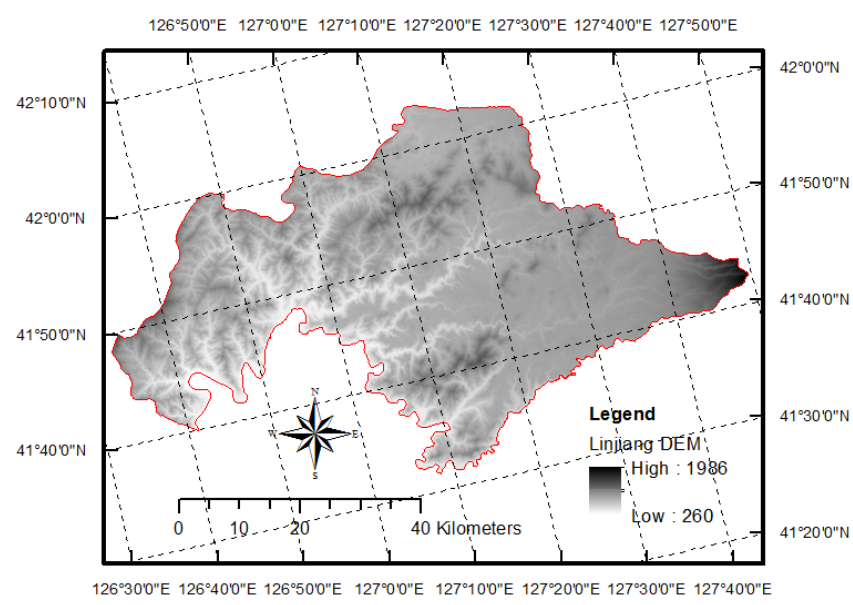

Fig. 1. The location map of Linjiang area.

Since the limitation of production activities has been broken from 19 century, the increasing population and predatory resource development have led to severely damage on ecological environment in Changbai Mountain. In the process of economic development, because of the lack of comprehensive cognition of ecological environment, the unreasonable pursuit of timber production had resulted in the deforestation with a cutting down of a large area of forest, and in order to mitigate the food crisis causing by the sharp growth of population, the forest land was converted to farmland in many places. Moreover the demand of fuelwoods and ginseng cultivation further exacerbated the destruction of ecological environment with the majority of forest in Changbai Mountain. 


\section{METHOD AND DATASET}

\section{A. Research Method}

Risk assessment is a probabilistic method to analyze the probability of occurrence of uncertain events and the potential loss caused by it. And it was broadly used for human health assessment to evaluate the impact of chemical pollution on human's body [9]. Barnthouse and Sute tried to apply the framework of human health assessment into ecological risk assessment in 1984 to analyze the environmental risk caused by the synfuel derived contaminants [10]. This attempt reflected the differences between ecological risk assessment and human health assessment, and the process of ecological risk assessment starts from the identification of risk source, ecological description and endpoint selection [11]. The ecological risk assessment took consideration of the prior analysis, exposure evaluation and impact assessment at the same time. According to a definition provided by the environmental protection agency of USA (1998), ecological risk assessment is "a process to quantitatively analyze and evaluate the probability that the environment might be impacted as a result of exposure to one or more environmental stressors like climate change and land cover change in a certain period" [12]. As one kind of risk, the ecological risk is also constituted by hazard, exposure and vulnerability, therefore, the assessment process can be divided into the following phases:

\section{1) Identification of risk sources}

It is important to know what is the sources of risk in the evaluation process, and the risk source also called as interference or pressure, refers to one or more chemical or physical sources that might adversely affect the ecosystem and its components [13]. In this paper, the relationship between land use change and ecological environment risk was analyzed from the viewpoint of landscape ecology, which indicate that the impact of land use change exceed the self-capacity of environment might lead to the degradation of ecological system such as the fragmentation of landscape and then result in changes of vegetation biotope, soil degradation and biodiversity reduction which cannot be recovered by itself. Therefore, a series of representative indicators of risk source were selected from factors related with land use change, including the urbanization level, proportion of agricultural land and road density.

\section{2) Vulnerability assessment of risk receptor}

The vulnerability assessment is also an important part of risk evaluation, and the vulnerability means the sensitivity to a disturbance and the adaptive capacity of the ecosystem [14]. When the ecosystem is affected by various interference factors that exceed their adaptive capacity, it will appear some irreversible damage or degradation, such as decline in productivity and reduce the regulation ability of environment. The landscape disturbance degree and land degradation degree is the representation indicators to reflect the ecosystem vulnerability. The higher the landscape disturbance degree, the worse the resistance and resilience to the outside interference. Similarly, the higher the land degradation degree, the system will be more sensitive to the interference and the higher the vulnerability of the ecosystem.

3) Exposure evaluation of risk receptor
Exposure means the degree of the receptor exposed to the risk source, and the risk receptor may be not only organism, but also refers to non-living organism [15]. Considering that the land use change mainly affects the structure and function of the ecosystem, the biological abundance degree, vegetation cover degree, soil organic matter content and ecosystem service value were chosen as indicators to evaluate the exposure level.

\section{B. Data}

Two scenes of Landsat TM 5 data (path 116, 117 and row 31) at September 2010 were downloaded freely from the USGS center through the internet (http://landsat.usgs.gov/). And the images were re-projected to Albers equal area conic projection and the study site was masked out by ENVI. The two images was obtained at the vegetation growth period, thus it can better response with the condition of vegetation growth. Due to the high spatial resolution at $30 \mathrm{~m}$, it is adequate to interpret the land use type in this area. Moreover, a topographic map at scale of 1:50,000 and an administrative map obtained from local government were used as ancillary data to get land use map. The soil data was from the national soil survey data.

\section{RESULTS}

\section{A. Index System of Ecological Risk Assessment}

For different ecosystem, it is essential to choose appropriate research methods and evaluation indicators in ecological risk assessment. However, due to the complex constitution of ecosystem itself, the evaluation indicators of ecological risk assessment still need to be improved [16]. Therefore, in this paper, the index system of ecological risk assessment based on land use change was discussed through the comparative analysis of prior research about ecological risk assessment at home and abroad. In addition, the index system was established under the theory of natural disaster risk management (Table I).

TABLE I: INDEX SYSTEM OF ECOLOGICAL RISK ASSESSMENT

\begin{tabular}{clll}
\hline \hline Index & Factors & Indicators & Weight \\
\hline Ecologic & Hazard & Urbanization level & 0.1738 \\
al risk & & Road density & 0.0525 \\
index & & Agricultural land proportion & 0.1011 \\
& \multirow{2}{*}{ Exposure } & Integrated land use degree & 0.1548 \\
& & Biological diversity & 0.0681 \\
& & Vegetation coverage degree & 0.0832 \\
& Soil organic matter content & 0.0581 \\
& Vulnerability & Ecological service value & 0.0842 \\
& & Landscape disturbance level & 0.0766 \\
& & Land degradation degree & 0.0867 \\
& & Water pollution index & 0.0609 \\
\hline \hline
\end{tabular}

The Analytic Hierarchy Process (AHP) method [17] was used to identify the weight of each indicator. Firstly, a hierarchical structure model was established, and then hierarchical scoring was conducted by several experts based on the measured indicator data. Secondly, the comparison matrix was obtained through the hierarchical scoring. Finally, the consistency test was used to check the credibility of expert scoring. If the consistency random index is smaller than 0.1 , the result of comparison matrix can be considered to have a 
satisfactory consistency and credibility. However, in practical applications, since each expert has difference cognition of a same problem, inevitably the subjectivity might be existing in the process. In order to overcome this shortcoming, the information entropy was introduced to revise the weight of each indicator in this paper.

The concept of entropy [18] was firstly introduced into the field of thermodynamics, until now, it has been applied in various areas of social and economic. In the field of information systems, the entropy is a measure of information stability, the larger the entropy, the more unstable the system is, and the less the useful information was contained. In the contrast, the smaller the entropy is, the more stable the system tends to be, and the more the useful information was included.

After the amendment by the information entropy, the final weight of each indicator was obtained as follows:

$$
\begin{gathered}
W=(0.4822,0.2936,0.2242) ; \\
W_{l}=(0.3604,0.1088,0.2096,0.3212) ; \\
W_{2}=(0.2318,0.2833,0.1980,0.2869) ; \\
W_{3}=(0.3418,0.3866,0.2716)
\end{gathered}
$$

\section{B. Ecological Risk Assessment Model}

According to the risk formation theory, it can be known that the ecological risk in Linjiang area is a consequence of combined effect of risk source, vulnerability of receptor and exposure of receptor. The hazard degree to the natural environment and ecosystem tends to be higher when land use changes severely, which might cause a higher ecological risk value. The higher exposure degree means more potential receptor might be affected by the risk source, and the impact on environment tends to be greater when ecological risk happens. Meanwhile, the vulnerability of receptor showed a positive correlation with the ecological risk value, the higher the vulnerability the receptor tend to be more easily affected by ecological risk. Therefore, the ecological risk situation was quantitatively depicted through construction of ecological risk index in this paper. The formula is as follows:

$$
E R I=H \times E \times V
$$

In formula (1), the ERI means ecological risk index, $H$ is hazard value, $E$ express the exposure degree and $V$ is the vulnerability degree.

Among the factors affecting ecological risk, the contribution rate of each indicator is different. And the composite index value of hazard, vulnerability and exposure can be obtained by comprehensive index method respectively:

$$
\begin{aligned}
& H=\sum_{i=1}^{3} W_{H i} X_{H i} \\
& E=\sum_{i=1}^{4} W_{E i} X_{E i} \\
& V=\sum_{i=1}^{3} W_{V i} X_{V i}
\end{aligned}
$$

In which, the $X_{i}$ is the quantization value of indicator $i, W_{i}$ is the weight of indicator $i$. using the above formula, we can get the distribution map of hazard, vulnerability and exposure in Linjiang area.

Based on the analysis above, combined with the weight of each evaluation indicator, the ecological risk assessment model can be established as follows:

$$
E R I=R \cdot W_{R} \times E \cdot W_{E} \times V \cdot W_{V}
$$

The ERI is ecological risk index, indicating the range of regional ecological risk value. And the higher the index, the greater the ecological risk value and the worse the quality of the ecological environment. In contrast, the lower the index, the smaller the ecological risk value and the better the quality of environment. $H, V, E$ means hazard, vulnerability and exposure respectively. $W$ is the weight of each factor.

\section{Ecological Risk Assessment in Linjiang Area}

Combined with the hazard identification, vulnerability and exposure evaluation, the geographic information systems (GIS) was used as a tool to analyze the integrated ecological risk and a distribution map of ecological risk was obtained (Fig. 2).

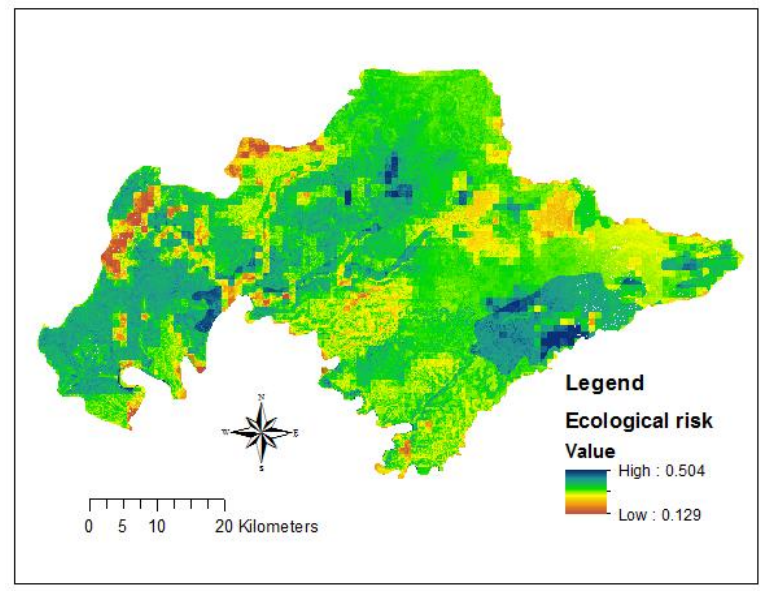

Fig. 2. The distribution map of ecological risk in Linjiang area in 2010.

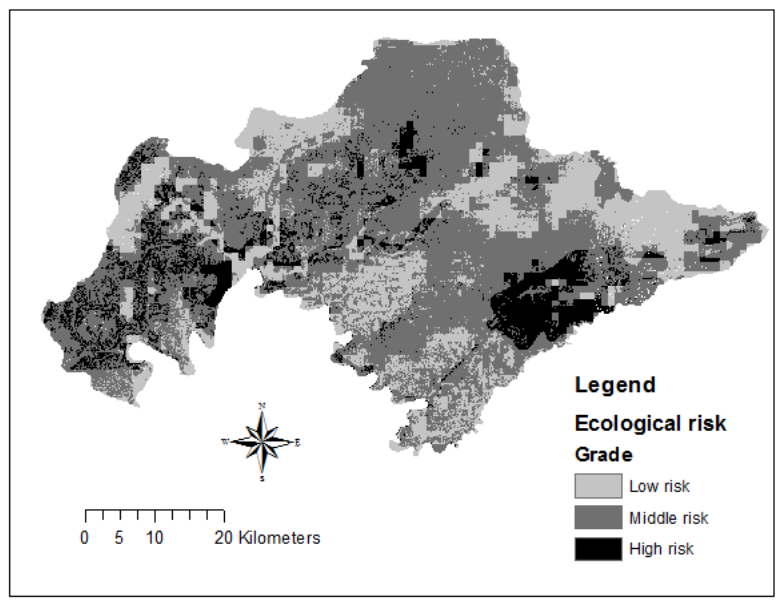

Fig. 3. The regionalization of ecological risk in Linjiang area in 2010.

As it can be seen from the Fig. 2, because of the special geographic location, the overall ecological risk value of Linjiang area was not so high in 2010 , and the highest risk value is only about 0.5 . The region with high ecological risk 
almost located in the eastern part of Linjiang area, and it might be a result of population growth. The agricultural land expanded dramatically to meet the need of people's living, which brings great stress to the landscapes in this area and leads to the fragmentation of landscape. In addition, with the topographical condition, the water retention capacity of soil is poor, thus the ecological impact of soil erosion disaster in this area is greater. All these conditions have led to a larger ecological risk value in this area.

We used the natural breaks method to divide the ecological risk level of the study area into low risk region, middle risk region and high risk region, showed in Fig. 3. Using the statistical function of GIS, it can be obtained that, the most part of the study area have a middle risk value, occupied $55.42 \%$ of total area. The high risk region occupied about $21.79 \%$ of Linjiang area, and the environment was threatening by various factors. The environmental conservation measurement should be implemented in this area The low risk region is about $22.79 \%$ and mainly located in the northern part of the study area.

\section{CONCLUSION}

Considering the availability of dataset, the social and economic data was obtained at administrative level. In order to achieve the consistency of evaluation units, it was re-sampled to a gird scale at $30 \times 30 \mathrm{~cm}$ through interpolation. From the result, we can understand that although the overall ecological risk value is not so high, the potential ecological risk caused by land use change cannot be ignored. Therefore, environmental conservation measurement should be taken to protect the environment.

\section{REFERENCES}

[1] R. A. Lopez, A. O. Adelaja, and M. S. Andrews, "The effects of suburbanization on agriculture," American Journal of Agricultural Economics, vol. 70, pp. 346-358, 1988.

[2] Q. Xu, "Studies on the land use change and ecological risk assessment in Puan City, China," M.S. thesis, Dept. Physical Geography, Guizhou Normal Univ., Guizhou, China, 2009.

[3] J. Wang, B. S. Cui, and J. Liu, "Effect of land use and its change on ecological risk in the Lancang River watershed of Yunnan province at the landscape scale," Acta Scientiae Circumstantiae, vol. 28, pp. 269-277, 2008.

[4] W. Zhanf, H. Y. Zhang, X. H. Wang, and H. Q. Zhang, "Land use changes and its influences on ecosystem service value over the newly reclaimed area of Yili, Xinjiang province, China," Resource Science, vol. 31, no. 12, pp. 2042-2046, Dec. 2009.

[5] X. X. Yu, G. S. Yang, and Y. Wang, "Advances in researches on environmental effects of land use/cover change," Scientia Geographica Sinica, vol. 24, no. 5, pp. 627-633, Oct. 2004

[6] Y. Liang, "Ecological risk assessment of land use change in Jibei Area," M.S. thesis, Dept. Physical Geography, Hebei Normal Univ., Hebei, China, 2010.

[7] L. J. Zhou, X. P. Zhang, and S. Chen, "Land use change and ecological risk assessment of Zhalong Natural Protection Area," Journal of Natural Disaster, vol. 18 no. 2, Apr. 2009.

[8] S. C. Wei, C. F. Wu, Y. Yang, M. Y. Huang, and Z. R. Yang, "Land use change and ecological security in Yellow River delta based on RS and GIS technology: A case study of Dongying city, China," Journal of Soil and Water Conservation, vol. 22, no. 1, Feb. 2008.

[9] J. Cairns, K. L. Dickson, and A. K. Maki, "Estimating the hazard of chemical substance to acquatic life," Hydrobiologia, vol. 64, pp 157-166, 1979.

[10] G. W. Suter, L. W. Barnthouse, C. F. Bases et al., "Environmental risk analysis for direct coal liquefaction," ORNL/TM-9074, USA, 1984.

[11] G. W. Suter, T. Vermeire, and W. Munns, "Framework for the integration of health and ecological risk assessment," Human and Ecological Risk Assessment, vol. 9, pp. 281-303, 2003.

[12] USEPA, "Guidelines for ecological risk assessment," Federal Register, vol. 63, pp. 26846-26924, May, 1998.

[13] J. Q. Zhang, N. Okada, and H. Tatano, "Integrated natural disaster risk management: Comprehensive and integrated model and Chinese strategy choice," in Proc. 5th Annu. IIASA-DPRI Forum on Integrated Disaster Risk Management, Sept. 2005.

[14] H. J. Lange, S. Sala, and M. Vighi, "Ecological vulnerability in risk assessment - A review and perspectives," Science of Total Environment, vol. 408, pp. 3871-3879, 2010.

[15] USEPA, "Framework for ecological risk assessment," EPA/630/R-92/001, Risk Assessment Forum, Feb. 1992.

[16] F. Li, X. S. Liu, and D. Hu, "Evaluation method and index system of eco-city development: A case study in Dafeng city of Jiangsu province, China," Chinese Journal of Applied ecology, vol. 18, pp. 2006-2012, Sep. 2007

[17] R. W. Saaty, "The analytic hierarchy process - What it is and how it is used," Mathematical Modelling, vol. 9, pp. 161-176, 1987.

[18] X. C. Zhang and M. Y. Fu, "Selection method for scene matching area based on information entropy," System Engineering and Electronics, vol. 33, no. 5, pp. 1089-1094, May 2011.

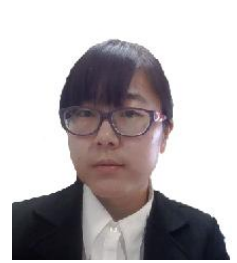

Zou Taohong was born in Hubei province in China in 1986. She earned her bachelor degree in management from Jilin Agricultural University in China in 2008, and followed by a master degree in science from Northeast Normal University in China in 2012. Currently she is pursuing her $\mathrm{PhD}$ degree from University of Tsukuba in Japan.

She has a few publications to her name during master program and she is interested in ecological risk assessment, forest conservation and measurement. 